\title{
Chronic Stress and Depressive Disorders in Older Adults
}

\author{
Jason R. Dura \\ Department of Psychiatry \\ Ohio State University College of Medicine \\ Janice K. Kiecolt-Glaser \\ Department of Psychiatry \\ Ohio State University College of Medicine
}

\author{
Karl W. Stukenberg \\ Ohio State University
}

\begin{abstract}
Current and lifetime rates of Diagnostic and Statistical Manual (rev. 3rd ed.) disorders were compared in 86 older adults caring for a spouse with a progressive dementia and 86 sociodemographically matched control subjects. Dementia caregivers were significantly more dysphoric than noncare givers. The frequencies of depressive disorders did not differ between groups in the years before care giving, and there were no group differences in first-degree relatives' incidence of psychiatric disorder. During the years they had been providing care, $30 \%$ of care givers experienced a depressive disorder (major depression, dysthymia, or depression not otherwise specified) versus $1 \%$ of their matched controls in the same time period. Only two care givers who met criteria during care giving had met criteria for a depressive disorder before care giving, and family history was not even weakly related to the identification of at-risk care givers. In contrast to these group differences in depressive disorders, there were no significant differences in other Axis I disorders either before or during care giving. Thus, the chronic strains of care giving appear to be linked to the onset of depressive disorders in older adults with no prior evidence of vulnerability.
\end{abstract}

Chronic life strains involve exposure to problems that are continuously demanding or difficult circumstances that do not change (Breslau \& Davis, 1986; Pearlin, Lieberman, Menaghan, \& Mullan, 1981). Research on the psychopathological consequences of chronic stress is often difficult because of the problems involved in understanding the direction of causality (i.e., determining whether the stressor represents a cause or a consequence of a psychiatric disorder) (Depue \& Monroe, 1986). This study's focus on the consequences of care giving for a cognitively impaired spouse provided a means of examining vulnerability in individuals who were in no way responsible for the stressor's occurrence.

Providing care for a spouse with senile dementia of the Alzheimer's type (SDAT) or other progressive dementias is associated with many hardships (Kiecolt-Glaser, Dyer, Shuttleworth, Ogrocki, \& Speicher, 1987; Light \& Lebowitz, 1989). The illness's course is unpredictable, as is the rapidity of decline; the only certainty is the patient's eventual death. Survival time after SDAT onset ranges from 8 to over 20 years (Butler \& Lewis, 1982). Many common dementia-related behaviors have severe consequences for care givers' daily lives (e.g, patients may become delusional or may develop other psychotic symptoms). As the illness progresses, care givers must be increasingly vigilant, since dementia patients can wander off or injure them-

This research was supported by National Institute of Mental Health Grant MH42096 to the third author and by funds from the Office of Geriatrics and Gerontology, the Ohio State University College of Medicine.

Correspondence concerning this article should be addressed to Jason R. Dura, who is now at the Department of Psychology, Bowling Green State University, Bowling Green, Ohio 43403-0228. selves. In the final stages, patients need to be fed, bathed, toileted, and clothed (Rabins, Mace, \& Lucas, 1982; Zarit, Orr, \& Zarit, 1985).

Although care giving for a demented family member is clearly associated with increased dysphoria (Light \& Lebowitz, 1989), the association between care giving and syndromal depressive disorders has been less clear. Researchers reviewing studies of depression in dementia care givers suggested that current disorder rates range from $14 \%$ to $81 \%$ of the samples (Coppel, Burton, Becker, \& Fiore, 1985; Morris, Morris, \& Britton, 1988); however, syndromal depression was inferred from self-report scales in most of these studies. Only three published studies used psychiatric diagnostic interviews that required rating standardized criteria.

Gallagher, Wrabetz, Lovett, Del Maestro, and Rose (1989) studied 112 dementia care givers and 78 persons who were caring for a relative with a significant physical disorder but no cognitive impairment who had sought treatment in a psychoeducational program for care-giving-related distress. On the basis of Research Diagnostic Criteria (RDC; Spitzer, Endicott, \& Robins, 1978), care givers in both groups were comparably depressed: About $25 \%$ currently met major depression criteria, $20 \%$ were experiencing a current episode of minor depression, and another $2 \%$ to $6 \%$ had been depressed episodically for the prior two years.

Studying only spousal care givers, on the basis of the RDC Coppel et al. (1985) found that 28 of 68 SDAT spousal care givers were currently depressed, and 27 additional care givers had been previously depressed during care giving. Combined, they found that $81 \%$ of their sample had a depressive disorder at some point during care giving. Spouses had the highest incidence of depression among the 46 care givers for dementia pa- 
tients seen at a geriatric diagnostic and treatment service $(\mathrm{Co}-$ hen $\&$ Eisdorfer, 1988). Five of the 22 care givers who lived with the patient met criteria for unipolar depression when interviewed by a psychiatrist who used Diagnostic and Statistical Manual of Mental Disorders (rev. 3rd ed; DSM-III-R; American Psychiatric Association, 1987) criteria, but not within the format of a structured clinical interview. Seven additional subjects currently met criteria for adjustment disorder with depressive symptoms; no care giver who lived away from the patient was judged to be clinically depressed. Overall, 55\% experienced clinical depression.

The RDC criteria for mild depression, used in the first two studies (Coppel et al, 1985; Gallagher et al, 1989), are less stringent for any depressive disorder diagnosis than $D S M-I I I-R$ criteria, the current preeminent clinical standard that was used in the third study (Cohen \& Eisdorfer, 1988). Thus, differences in diagnostic criteria and varied sources of care-giver recruitment (treatment site or not) may be related to variance in disorder rates.

In examining the psychopathological consequences of care giving for a demented spouse, the current study differs from prior studies in several important ways. First, we examined subjects' lifetime history of $D S M-I I I-R$ disorders both before and during care giving as well as the incidence of disorder in their first-degree relatives; although personal and family history mediate vulnerability (Depue \& Monroe, 1986), they have not been addressed in prior care-giver research. Second, most studies have focused only on affective disorders, and no study to date has provided a comprehensive survey of other current and lifetime psychiatric diagnoses in care givers. It is possible that care giving is related to onset of a myriad of other Axis I psychiatric disorders (Popkin, Callies, Lentz, Colon, \& Sutherland, 1988). Third, no prior study addressing syndromal disorders has used a comparison sample. We used a sociodemographically matched control group with individual matching of subjects (i.e., we compared timing of affective disorders for each care giver with his or her control). This strategy permitted the examination of affective disorder rates during the same developmental and historical time period in similar older adults who were not caring for a demented family member. Fourth, our care givers and controls were recruited widely from the community, and we assessed them both at our university clinic office and at home. Care givers who were unable or unwilling to travel to a clinic site despite the availability of free taxi service were significantly more distressed than those who came for clinic assessment (Dura \& Kiecolt-Glaser, in press).

We hypothesized that the stresses of care giving would give rise to a greater cumulative incidence of depressive disorders during the care-giving period than found during the same time period in well-matched controls. Care givers with a history of depressive disorder before care giving were expected to be more vulnerable during care giving than individuals without a history, as were care givers with a family history of psychiatric disorder.

\section{Method}

\section{Subjects}

Care givers were recruited from three local dementia evaluation centers in area hospitals, neurologists' referrals, the city's Alzheimer's
Disease and Related Disorders Association (ADRDA) support groups, the monthly ADRDA newsletter, respite care programs, and governmental care-giver support programs. Care givers were required to provide five or more hours of care giving per week to their demented spouse. Thirty-two care givers were reluctant to leave their spouse unattended or bring them to the university despite free transportation and were interviewed at home.

Comparison subjects were recruited through newspaper advertisements, church groups, notices posted in senior citizen centers, and referrals from other participants; potential comparison subjects who reported any care-giving activities were excluded. Care givers and comparison subjects were individually matched on sex, age, and education; we used education as a proxy for socioeconomic status because many of our care givers were older women who had not worked outside of the home (Rook, 1984).

The subjects were part of a larger study on chronic stress, immunity, and health. Subjects were excluded if they had major immunologically related health problems such as cancer or recent surgeries. All subjects were paid $\$ 30$ for participation in the study.

\section{Psychiatric Diagnostic Data}

The Structured Clinical Interview for $D S M-I I I-R$, nonpatient version (SCID-NP), is designed to enable a clinically trained interviewer to make reliable and valid $D S M-I I I-R$ diagnoses (Riskind, Beck, Berchick, Brown, \& Steer, 1987; Spitzer, Williams, Endicott, \& Gibbon, 1987). Interviews were done by advanced clinical psychology graduate students or by a clinical psychology postdoctoral fellow. The diagnostic interviews provided current and lifetime incidence of affective disorders with the approximate date(s) of onset noted.

Interrater reliability for SCID-NP diagnoses was calculated using randomly selected audiotaped interviews for 41 (24\%) of the subjects. The kappa coefficient of .92 for depressive disorders demonstrates excellent interrater reliability (Riskind et al, 1987).

As suggested by Becker and Morrissey (1988) and Gallagher et al. (1989), interviewers were careful to attribute symptoms to depression only when their presence or intensity was not explicable simply on the basis of gross characteristics of the care-giving situation itself or related to normal changes associated with aging. For example, in evaluating changes in sleep, interviewers inquired about current sleep quality compared with the last few years, not current sleep quality compared with that at a much earlier age; similarly, if a dementia patient had a disrupted diurnal wake/sleep cycle and woke the care giver, this was not considered a sleep disturbance.

Psychopathology in first-degree relatives was assessed using Family History Research Diagnostic Criteria (FH-RDC) (Andreasen, Endicott, Spitzer, \& Winokur, 1977), a method that has good to excellent reliability for specific FH-RDC disorders but not for the residual category of other psychiatric disorders (Zimmerman, Coryell, Pfohl, \& Stangl, 1988). This interview followed the SCID and used hierachical probes to assess history in parents, siblings, and children across 12 categories; only data from parents and siblings were used in the present study, since data from children also reflect the spouse's genetic and behavioral heritage. The categories were chronic schizophrenia, schizoaffective disorder, depressive disorder, manic disorder, senile organic brain syndrome, unspecified functional psychosis, aicoholism, drug use disorder, antisocial personality, other psychiatric disorder, bipolar, and recurrent unipolar.

For care givers, onset of care giving was obtained from a separate questionnaire so that a determination could be made as to whether the disorder(s) began during care giving. The date of onset of care giving was determined by reviewing need for assistance from the point of the first neurological evaluation backward in months. Care givers were required to give examples of specific instances of providing assistance 
in order for care giving to be scored as ongoing. Total time of care giving was then determined by the length of time since assistance began. For control subjects, the onset date of care giving for their matched care giver was used for comparison purposes; for example, if the care giver had been providing care for five years, we examined the matched control subject's incidence of affective disorder during the last five years.

\section{Depression Scales}

The Hamilton Depression Rating Scale (HDRS), a 24-item interviewer-rated measure of depression, provided information of depressive symptomatology for the week before the interview (Hamilton, 1967). Interrater reliability for the HDRS, calculated for $9 \%$ of the subjects using audiotapes, was. 74 .

The short form of the Beck Depression Inventory (BDI), a 13-item subset of the original instrument (Beck \& Beck, 1972), was used. It is commonly used to screen for depression, and has been used with older populations in part because it has fewer somatically laden items than more biologically based scales (Hammen, 1980). Each cluster of items presents four sentences, and the subjects endorse the sentence or sentences that best describe the way they have been feeling in the past week.

\section{Dementia Assessment}

Family members' ratings can provide one source of reliable data on dementia patients' functioning. For example, in a sample of 82 elderly patients, the majority of whom had an SDAT diagnosis, there was a high degree of concordance between family and staff members' ratings regarding 10 areas of patient functioning (Reifler, Cox, \& Hanley, 1981).

The Blessed Dementia Scale (BDS; Blessed, Tomlinson, \& Roth, 1968) was developed to measure negative changes in a demented person's abilities across daily living, self-care, and personality domains. Higher scores on this 22-item scale denote greater decrements in ability, with a potential range of 0 to 28 . BDS scores have been correlated with both senile plaque count during postmortem histological examination as well as impairments in neuropsychological testing, and can be used to differentiate degree of dementia (Blessed et al., 1968; Erkinjuntti, Hokkanen, Sulkava, \& Palo, 1988).

The Memory and Behavior Problem Checklist (MBPC; Zarit, Reever, \& Bach-Peterson, 1980) measures behavioral excesses and deficits in dementia patients, and the care giver's reaction to those problems. The 29 items include some of the problems most distressing to care givers (e.g, the patient's inability to dress and feed himself or herself, incontinence, inability to communicate, hiding things, and inability to recognize familiar people). Factor analytic research with the MBPC has shown three discrete domains: need for assistance with self-care and instrumental activities of daily living, memory problems and psychiatric symptoms, and communication difficulties (Dura, Bornstein, \& Kiecolt-Glaser, in press). The scale provides three scores: a measure of the frequency of problem behaviors, a measure of associated care-giver distress, and a third score that combines frequency and reaction to produce a summary measure. The MBPC measures current symptoms and associated subjective care-giver distress, not impairment of the patient per se, as many behavior problems are most prevalent in the middle stages of dementia.

The Global Deterioration Scale (GDS; Reisberg, Ferris, DeLeon, \& Crook, 1982) provided a dementia stage rating in patients who have been previously diagnosed with dementia. The scale has well-described anchor points, from 1 (no cognitive decline) to 7 (very severe cognitive decline). Ratings were based on care givers' reports of the affected family members' history and current functioning. Interrater
Table 1

Characteristics of Care Givers and Comparison Subjects

\begin{tabular}{lcc}
\multicolumn{1}{c}{ Variable } & $\begin{array}{c}\text { Care } \\
\text { givers }\end{array}$ & $\begin{array}{c}\text { Comparison } \\
\text { subjects }\end{array}$ \\
\hline Sex & & \\
Male & 28 & 28 \\
Female & 58 & 58 \\
Age & & \\
$M$ & 68.13 & 66.86 \\
$S D$ & 8.36 & 8.25 \\
Education & & \\
Partial high school or less & 9 & 7 \\
High school graduate & 24 & 22 \\
Partial college & 23 & 19 \\
College graduate & 14 & 23 \\
Graduate training & 16 & 15 \\
Hamilton Depression Rating Scale* & & \\
$M$ & 8.16 & 1.92 \\
$S D$ & 6.56 & 2.49 \\
Beck Depression Inventory* & & 3.45 \\
$M$ & 6.94 & 3.80 \\
$S D$ & 6.30 & \\
\hline
\end{tabular}

$* p<.0001$.

reliability using the GDS was assessed by comparing ratings made by the original interviewer with those of a clinical psychologist with geriatric assessment experience. The psychologist, unaware of the prior rating, based the ratings on information from the BDS and $M B P C$. Reliability was computed for 18 randomly chosen subjects (35\%); the Pearson product-moment correlation between the original and comparison GDS scores was excellent $(r=.92)$.

\section{Results}

\section{Subject Characteristics}

The demographic characteristics of the 86 care givers and 86 control subjects are presented in Table 1 . The matching procedures were successful in producing groups that did not differ on age, education, or income, $F \mathrm{~s}<1$. The modal subjects reported an annual family income between $\$ 20,000$ and $\$ 30,000$. The majority of subjects were Caucasian ( $95 \%$ of care givers and 93\% of controls). Most non-care givers were married (69\%); however, $19 \%$ were widowed, $12 \%$ were divorced, and 1 comparison subject had never married. Although we did not match our groups on marital status, the inclusion of divorced and widowed control subjects actually worked against confirmation of the experimental hypotheses, since intact marriages are associated with lower rates of psychopathology (Kessler, Price, \& Wortman, 1985).

Care givers had been care giving for a mean of 74.21 months $(S D=113.80)$ and reported spending a mean 4.45 hours per day care giving $(S D=3.13)$. Sixty-seven of the care givers cared for their spouse in their own home, while the remaining 19 cared for patients who were institutionalized.

Fifty-one of the care givers' spouses had an SDAT diagnosis, 3 were diagnosed with multiinfarct dementia, 26 with Parkinson's disease, 2 with Huntington's disease, 1 with Picks disease, and 3 with an unspecified dementia. Seventy percent had received their diagnosis at one of three local neurology centers 
Table 2

Frequency of Depressive Disorders by Group

\begin{tabular}{|c|c|c|}
\hline & $\begin{array}{c}\text { Care } \\
\text { givers } \\
(n=86)\end{array}$ & $\begin{array}{c}\text { Comparison } \\
\text { subjects } \\
(n=86)\end{array}$ \\
\hline \multicolumn{3}{|l|}{ Current depressive disorders } \\
\hline Major depressive disorder & 5 & 0 \\
\hline Dysthymic disorder* & 7 & 0 \\
\hline $\begin{array}{l}\text { Depressive disorder not } \\
\text { otherwise specified }\end{array}$ & 8 & 0 \\
\hline \multicolumn{3}{|l|}{ Cumulative depressive disorders } \\
\hline \multicolumn{3}{|l|}{ During care giving } \\
\hline Major depressive disorder* & 8 & 1 \\
\hline Dysthymic disorder ** & 10 & 0 \\
\hline $\begin{array}{l}\text { Depressive disorder not } \\
\text { otherwise specified** }\end{array}$ & 8 & 0 \\
\hline $\begin{array}{l}\text { Before care giving } \\
\text { Major depressive disorder }\end{array}$ & 7 & 11 \\
\hline Dysthymic disorder & 0 & 1 \\
\hline $\begin{array}{l}\text { Depressive disorder not } \\
\text { otherwise specified }\end{array}$ & 1 & 0 \\
\hline
\end{tabular}

Note. For comparison subjects, the date of onset of care giving for their matched care giver was used for comparison purposes (e.g., if the care giver had been providing care for five years, we examined the non-care giver's incidence of depressive disorders during the last five years).

$* p<.05$. ${ }^{* *} p<.01$.

that used the National Institute of Neurological and Communicative Disorders and Stroke/ADRDA work-group standards for probable SDAT (McKhann et al., 1984).

The majority of the care givers' spouses were severely demented. Only $15(18 \%)$ subjects were classified within Stages 2 through 4 on the GDS; $5(6 \%)$ were classified in Stage 2 (forgetfulness), 5 (6\%) in Stage 3 (early confusional), and $5(6 \%)$ in Stage 4 (late confusional). In contrast, the majority clearly fell in later stages: $24(28 \%)$ in Stage 5 (early dementia), $26(30 \%)$ in Stage 6 (middle dementia), and 21 (24\%) in Stage 7 (late dementia).

\section{Past and Current Depressive Disorders}

Before care giving, 8 care givers and 12 comparison subjects reported a depressive disorder; all of these were cases of major depression, except for 1 care giver's case of depression not otherwise specified (NOS) and 1 comparison subject's case of dysthymia. During the care-giving period, care givers reported significantly more depressive disorders than did comparison subjects, 26 of $86(30 \%)$ versus 1 of $86(1 \%), \chi^{2}(1, N=172)=27.84, p<$ .001 , with diagnoses shown in Table 2 . Most noteworthy is the fact that only 2 of the 26 care givers who reported a depressive episode during the care-giving period reported a prior depressive episode; in both cases the prior episode was major depression.

More care givers $(8$, or $9 \%)$ reported cases of major depressive disorder than did comparison subjects $(1$, or $1 \%), \chi^{2}(1, N=$ $172)=4.22, p<.05$, Yates corrected. More care givers also reported cases of dysthymia $(10$ of 86 , or $12 \%$, vs. 0 of 86$), \chi^{2}(1$, $N=172)=8.66, p<.01$, Yates corrected, and depression NOS ( 8 of 86 , or $9 \%$, vs 0 of 86 ), $\chi^{2}(1, N=172)=6.42, p<.02$, Yates corrected.

Among care givers, 6 of 28 men (21\%) and 20 of 58 women
(34\%) reported a depressive episode while care giving, whereas 2 of 28 men (7\%) and 6 of 58 females $(10 \%)$ reported one before care giving. Among comparison subjects, 1 of 28 men (4\%) and 12 of 58 females (21\%) reported a depressive disorder at some point during their lives.

Among diagnosed care givers, depressed affect was the most consistent feature followed by loss of interest, fatigue, sleep disturbance, and suicidal ideation. About one third of care givers who met $D S M-I I I-R$ criteria during care giving had sought treatment for their depressive disorders. One had sought brief consultation, 6 had treatment lasting 2 to 12 months, and 2 had treatment lasting more than 12 months.

\section{Other Axis I Disorders}

In contrast to these group differences in depressive disorders during care giving, there were no significant differences in other Axis I disorders either before or during care giving. During care giving, 1 care giver met criteria for generalized anxiety disorder and 2 met criteria for adjustment disorder, whereas 1 comparison subject was diagnosed with a generalized anxiety disorder, 1 with a social phobia, and 1 with an adjustment disorder.

Before care giving, 1 care giver met criteria for social phobia, 3 met criteria for adjustment disorder, 1 met conversion disorder criteria, 1 met generalized anxiety disorder criteria, and 2 met alcohol abuse criteria. Among comparison subjects, 2 met criteria for alcohol abuse, 1 met criteria for generalized anxiety disorder, 1 met criteria for adjustment disorder, and 1 met criteria for psychotic disorder not otherwise specified.

\section{Family History}

Only 4 of the 26 care givers with depressive disorders during the years they were care giving had a family history of mental illness: One care giver with major depression had an alcoholic parent, 2 dysthymic care givers had siblings with affective disorders, and one care giver with depressive disorder NOS had a sibling with an unspecified psychiatric disorder. In contrast, 4 of the 7 care givers with major depressive disorder before care giving reported a family history of mental illness, as did 3 control subjects. Thus, although family history was associated with major depression in care givers before their care giving began, it was not reliably related to affective disorders during care giving.

\section{Vulnerability and Sociodemographic Variables}

Greater vulnerability to depressive disorders has been associated with lower education and lower income across a number of studies (Kessler et al, 1985; Schulz, Tompkins, \& Rau, 1988). Care givers who had met $D S M-I I I-R$ criteria during care giving had lower current incomes, averaging between $\$ 10,000$ and $\$ 15,000$, compared with an average income of between $\$ 15,000$ and $\$ 20,000$ for those not meeting criteria, $F(1,82)=5.32, p<$ .05 . Similarly, care givers who had met $D S M-I I I-R$ criteria during care giving were not quite as well educated, having attained on average a high school diploma or some college as opposed to 
some college or a college degree attained by those not meeting criteria during care giving, $F(1,84)=4.44, p<.05$. Neither age nor dementia state discriminated those who met criteria from those who did not, $F s<1$.

\section{Interviewer- and Self-Rated Depressive Symptoms}

As shown in Table 1, care givers' current mean interviewerrated depression on the HDRS was significantly higher than that found in the comparison subjects, $F(1,168)=68.44, p<$ .0001 . Analyses of variance for depressive symptoms included sex as a variable since women typically report more depressive symptoms than men (Kessler et al., 1985). Women's mean level of depression on the HDRS $(5.52, S D=5.95)$ was slightly higher than that of the men $(4.07, S D=5.55), F(1,168)=3.23$, $p<.10$. There was not a significant Group $\times$ Gender interaction, $F<1$. Similarly, care givers' mean self-rated depression was significantly higher than that of controls on the BDI, $F(1$, $149)=18.16, p<.0001$, and female care givers reported only slightly higher mean levels of current depression on the BDI (7.91, $S D=7.12)$ than male care givers $(4.70, S D=2.89), F(1$, $149)=4.15, p<.05$. Again, there was no significant interaction, $F(1,149)=1.86$. The latter scale had not been included in all subjects' packets.

Most studies on care giving have not found reliable relationships between depression in care givers and the extent of patient impairment (Haley, Levine, Brown, \& Bartolucci, 1987; Kiecolt-Glaser, Dyer, \& Shuttleworth, 1988; Quayhagen \& Quayhagen, 1988). The correlation between HDRS ratings and GDS stage was -.02; however, the range of GDS stages was truncated, as described earlier. Correlations between the HDRS and years spent care giving was $.31, p<.003$, while average hours spent per day in care giving correlated .19 with the HDRS.

As noted earlier, Cohen and Eisdorfer (1988) found significantly greater depression in at-home care givers. In our sample, the 67 care givers whose patient lived at home had a mean HDRS of $7.91(S D=6.91)$, while 18 care givers whose patient resided in a nursing home had a mean HDRS score of 8.83 $(S D=5.37), F<1$. Similarly, at-home care givers had a mean BDI score of $6.94(S D=6.40)$ compared with $6.93(S D=6.19)$ for those whose patient was institutionalized, $F<1$. At-home care givers spent an average of 5.29 hours/day in care giving, while care givers whose patient was in a nursing home spent 1.51 hours/day, $F(1,84)=28.52, p<.0001$. The former had spent an average of 5.88 years in care giving compared with 7.24 for the latter, $F<1$.

Cohen and Eisdorfer (1988) excluded from their study any care giver who was currently in a support group, while Gallagher et al. (1989) found differences between research volunteers and people who had sought treatment in a psychoeducational program for care-giving-related distress. To assess the possibility that those subjects in our study who were recruited from support groups differed from those who were not members, we compared depression scores for the two groups. Those care givers who were in a support group had mean HDRS scores of $8.61(S D=6.68)$ compared with $7.33(S D=$ 6.35 ) for those not in a support group, $F<1$. The mean BDI score was $7.79(S D=6.87)$ for group members, with mean BDI scores of $5.46(S D=4.96)$ in nonmembers, $F(1,64)=2.13$.

\section{Discussion}

Spousal care givers experienced significantly more depressive disorders during the years they had been providing care than did matched controls during the same developmental and historical time periods. In addition, care givers' incidence of depression, particularly major depression, was much higher than reports from epidemiological surveys of older community-dwelling adults, while the number of cases among comparison subjects was comparable to base rates found in epidemiological studies (Blazer, Hughes, \& George, 1987). Most noteworthy, however, was the fact that neither depressive disorders before care giving nor family history was even weakly related to identification of care givers at risk. Care givers with no personal or family history of depressive disorders were found to have developed depressive disorders concomitant with care giving. These data suggest that the chronic strains of care giving are related to the onset of depressive disorders in older adults with no prior evidence of vulnerability. Although our sample was relatively large, the limited numbers of non-Caucasians and men suggest caution in generalizing findings to these subgroups.

The finding that income and education were both lower for care givers who experienced a depressive disorder during the years they were care giving is consistent with considerable evidence that greater vulnerability for psychopathology is associated with lower socioeconomic status and lower income (Depue \& Monroe, 1986; Kessler et al., 1985). Lower socioeconomic status individuals are disadvantaged by having fewer resources in the face of any crisis, and the long-term demands of care giving could certainly exacerbate any prior deficiencies (Schulz et al, 1988).

As noted earlier, it is difficult to determine whether many chronic or acute stressors represent a cause or a consequence of a psychiatric disorder (Kessler et al, 1985). However, our spousal care givers had no responsibility for the occurrence of the stressor. Thus, these data lend weight to the argument that chronic stressors can make significant causal contributions to depressive disorders.

Of those care givers who met $D S M-I I I-R$ criteria for depressive disorders during care giving, about one third were major depressive disorder, one third were dysthymic disorder, and one third were depressive disorder NOS. Consistent with these data, a number of studies with older adults showed that minor depressive disorders appear to be about twice as prevalent as major depression (Parmelie, Katz, \& Lawton, 1989).

Dysthymic disorder and depressive disorder NOS have not been strongly associated with personal or family history; however, major depressive disorder is strongly associated with personal and family history (Becker \& Morrissey, 1988), and certainly might be expected to have made a prior appearance in older adults whose average age was 68 . The reliably elevated rates of major depression found across studies of care givers (Cohen \& Eisdorfer, 1988; Coppel et al., 1985; Gallagher et al, 1989) are significantly in excess of population base rates for older adults (Blazer et al., 1987), and provide convergent evi- 
dence that dementia care giving may elicit episodes of major depression even when no personal or family history of depression is present.

Depression appears to be the characteristic affective response to the burdens of care giving; anxiety is a very distant second (Gallagher et al, 1989). The specificity of the effect may follow from the nature of care givers' strain. Progressive dementias involve unpredictable and uncontrollable decline. Care givers have described the process as a kind of living bereavement, as they watch the disintegration of the personality and intellect of their spouse. Research abounds linking loss of control, unpredictable negative events, and spousal loss with depressive affect (e.g., Pagel, Becker, \& Coppel, 1985). It is our speculation that these features of care-giver strain are largely responsible for the present findings.

\section{References}

American Psychiatric Association. (1987). Diagnostic and statistical manual of mental disorders (Rev. 3rd ed.). Washington, DC: Author. Andreasen, N. C, Endicott, J., Spitzer, R. L., \& Winokur, G. (1977). The family history method using diagnostic criteria. Archives of General Psychiatry, 34, 1229-1235.

Beck, A. T, \& Beck, R. W. (1972). Screening depressed patients in family practice: A rapid technique. Postgraduate Medicine, 51, 8185.

Becker, J., \& Morrissey, E. (1988). Difficulties in assessing depressivelike reactions to chronic severe external stress as exemplified by spouse caregivers of Alzheimer patients. Psychology and Aging, 3, 300-306

Blazer, D., Hughes, D. C., \& George, L. K. (1987). The epidemiology of depression in an elderly community population. Gerontologist, 27, 281-287.

Blessed, G., Tomlinson, B. E., \& Roth, M. (1968). The association between quantitative measures of dementia and senile change in the cerebral grey matter of elderly subjects. British Journal of Psychiatry, 114, 797-811.

Breslau, N., \& Davis, G. C. (1986). Chronic stress and major depression. Archives of General Psychiatry, 43, 309-314.

Butler, R., \& Lewis, M. (1982). Aging and mental health: Positive psychosocial and biomedical approaches (3rd ed.). Columbus, $\mathrm{OH}$ : Charles E. Merrill.

Cohen, D., \& Eisdorfer, C. (1988). Depression in family members caring for a relative with Alzheimer's Disease. Journal of the American Geriatrics Society, 36, 885-889.

Coppel, D. B., Burton, C., Becker, J., \& Fiore, J. (1985). Relationships of cognitions associated with coping reactions to depression in spousal caregivers of Alzheimer's disease patients. Cognitive Therapy and Research, 9, 253-266.

Depue, R. A., \& Monroe, S. M. (1986). Conceptualization and measurement of human disorder in life stress research: The problem of chronic disturbance. Psychological Bulletin, 99, 36-51.

Dura, J. R, Bornstein, R. A., \& Kiecolt-Glaser, J. K. (in press). Refinements in the assessment of dementia-related behaviors: Factor structure of the Memory and Behavior Problem Checklist. Psychological Assessment: A Journal of Consulting and Clinical Psychology.

Dura, J. R., \& Kiecolt-Glaser, J. K. (in press). Sample bias in caregiving research. Journal of Gerontology.

Erkinjuntti, T., Hokkanen, L., Sulkava, R., \& Palo, J. (1988). The
Blessed Dementia Scale as a screening test for dementia. International Journal of Geratric Psychiatry, 3, 267-273.

Gallagher, D, Wrabetz, A, Lovett, S., Del Maestro, S, \& Rose, J. (1989). Depression and other negative affects in family caregivers. In $\mathrm{E}$. Light \& B. D. Lebowitz (Eds.), Alzheimer's disease treatment and family stress: Directions for research (pp. 218-244). Rockville, MD: National Institute of Mental Health.

Haley, W. E., Levine, E. G., Brown, S. L. \& Bartolucci, A. A. (1987). Stress, appraisal, coping and social support as predictors of adaptational outcome among dementia caregivers. Psychology and Aging, 2, 323-330.

Hamilton, M. (1967). Development of a rating scale for primary depressive illness. British Journal of Social and Clinical Psychology, 6, 278-296.

Hammen, C. L. (1980). Depression in college students: Beyond the Beck Depression Inventory. Journal of Consulting and Clinical Psychology, 48, 126-128.

Kessler, R. C., Price, R. H., \& Wortman, C. B. (1985). Social factors in psychopathology: Stress, social support, and coping processes. $A n$ nual Review of Psychology, 36, 531-572.

Kiecolt-Glaser, J. K., Dyer, C. S., \& Shuttleworth, E. C. (1988). Upsetting social interactions and distress among Alzheimer's disease family caregivers: A replication and extension. American Journal of Community Psychology, 116, 825-837.

Kiecolt-Glaser, J. K, Glaser, R, Dyer, C, Shuttleworth, E, Ogrocki, P, \& Speicher, C. E. (1987). Chronic stress and immunity in family caregivers for Alzheimer's disease victims. Psychosomatic Medicine, 49, 523-535.

Light, E., \& Lebowitz, B. D. (1989). Alzheimers disease treatment and family stress: Directions for research. Rockville, MD: National Institute of Mental Health.

McKhann, G., Drachman, D, Folstein, M., Katzman, R, Price, D, \& Stadlan, E. (1984). Clinical diagnosis of Alzheimer's disease: Report of the NINCDS-ADRDA work group under the auspices of the Department of Health and Human Services Task Force on Alzheimer's disease. Neurology, 34, 939-944.

Morris, R. G., Morris, L. W., \& Britton, P. G. (1988). Factors affecting the emotional well-being of the caregivers of dementia sufferers. British Journal of Psychiatry, 153, 147-156.

Pagel, M. D., Becker, J., \& Coppel, D. B. (1985). Loss of control, selfblame, and depression: An investigation of spouse caregivers of Alzheimer's disease patients. Journal of Abnormal Psychology, 94, 169182.

Parmelie, P. A., Katz, I. R., \& Lawton, M. P. (1989). Depression among institutionalized aged: Assessment and prevalence estimation. Journal of Gerontology, 44, M22-29.

Pearlin, L. I., Lieberman, M. A., Menaghan, E. G., \& Mullan, J. T. (1981). The stress process. Journal of Health and Social Behavior, 22, 337-356.

Popkin, M. K., Callies, A. L., Lentz, R. D., Colon, E. A., \& Sutherland, D. E. (1988). Prevalence of major depression, simple phobia, and other psychiatric disorders in patients with long-standing type I diabetes mellitus. Archives of General Psychiatry, 45, 64-68.

Quayhagen, M. P., \& Quayhagen, M. (1988). Alzheimer's stress: Coping with the caregiving role. Gerontologist, 28, 391-396.

Rabins, P. V, Mace, H. L., \& Lucas, M. S. (1982). The impact of dementia on the family. Journal of the American Medical Association, 248, 333-335.

Reifler, B. V, Cox, G. B., \& Hanley, R. J. (1981). Problems of mentally ill elderly as perceived by patients, families, and clinicians. Gerontologist, 21, 165-170.

Reisberg, B., Ferris, S. H., DeLeon, M. J., \& Crook, T. (1982). The 
Global Deterioration Scale for assessment of primary degenerative dementia. American Journal of Psychiatry, 139, 1136-1139.

Riskind, J. H, Beck, A. T, Berchick, R. J, Brown, G, \& Steer, R. A. (1987). Reliability of DSM-III diagnoses for major depression and generalized anxiety disorder using the structured clinical interview for DSM-III. Archives of General Psychiatry, 44, 817-820.

Rook, K. S. (1984). The negative side of social interaction: Impact on psychological well-being. Journal of Personality and Social Psychology, 46, 1097-1108.

Schulz, R, Tompkins, C. A. \& Rau, M. T. (1988). A longitudinal study of the psychosocial impact of stroke on primary support persons. Psychology and Aging, 3, 131-141.

Spitzer, R. L., Endicott, J, \& Robins, E. (1978). Research Diagnostic Criteria: Rationale and reliability. Archives of General Psychiatry, 35 , 773-782.

Spitzer, R. L, Williams, J. B. W, Endicott, J, \& Gibbon, M. (1987).
Structured Clinical Interview for DSM-III-R disorders-non-patient version (SCID-NP). New York: Biometrics Research Department, New York State Psychiatric Institute.

Zarit, S. H., Orr, N. K., \& Zarit, J. M. (1985). The hidden victims of Alzheimer's disease: Families under stress. New York: New York University Press.

Zarit, S. H., Reever, K., \& Bach-Peterson, J. (1980). Relatives of the impaired elderly: Correlates of feelings of burden. Gerontologist, 20, 649-655.

Zimmerman, M., Coryell, W, Pfohl, B, \& Stangl, D. (1988). The reliability of the family history method of psychiatric diagnosis. Archives of General Psychiatry, 45, 320-322.

Received June 7, 1989

Revision received December 4, 1989

Accepted December 20,1989 